Correction

\title{
Correction: Yao, P. et al. Rebuilding Long Time Series Global Soil Moisture Products Using the Neural Network Adopted the Microwave Vegetation Index. Remote Sens. 2017, 9, 35
}

\author{
Panpan Yao ${ }^{1,2}$ (1) , Jiancheng Shi ${ }^{2,3, *}$, Tianjie Zhao ${ }^{2,3}$, Hui Lu ${ }^{3,4}$ and Amen Al-Yaari ${ }^{5}$ \\ 1 Graduate School of University of Chinese Academy of Sciences, Beijing 100049, China; yaopp@radi.ac.cn \\ 2 State Key Laboratory of Remote Sensing Science, Institute of Remote Sensing and Digital Earth, \\ Chinese Academy of Sciences, Beijing 100101, China; zhaotj@radi.ac.cn \\ 3 The Joint Center for Global Change Studies, Beijing 100875, China; luhuil@tsinghua.edu.cn \\ 4 Ministry of Education Key Laboratory for Earth System Modeling, and Department of Earth System Science, \\ Tsinghua University, Beijing 100084, China \\ 5 INRA, UMR1391 ISPA, 33140 Villenave d'Ornon, France; amen.al-yaari@inra.fr \\ * Correspondence: shijc@radi.ac.cn; Tel.: +86-10-6483-8048
}

Received: 10 August 2017; Accepted: 14 August 2017; Published: 16 August 2017

After publication of the research paper [1], the authors wish to make the following correction to this paper. In the fourth line from the bottom in abstract, due to a typing error, " $\mathrm{RMSE}=0.84 \mathrm{~m}^{3} / \mathrm{m}^{3}$ " should be replaced with "RMSE $=0.084 \mathrm{~m}^{3} / \mathrm{m}^{3}$ ".

The changes do not affect the scientific results. The manuscript will be updated and the original will remain online on the article webpage, with a reference to this addendum. We apologize for any inconvenience caused by this mistake.

\section{Reference}

1. Yao, P.; Shi, J.; Zhao, T.; Lu, H.; Al-Yaari, A. Rebuilding Long Time Series Global Soil Moisture Products Using the Neural Network Adopting the Microwave Vegetation Index. Remote Sens. 2017, 9, 35. [CrossRef]

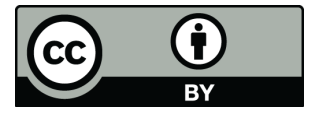

(C) 2017 by the authors. Licensee MDPI, Basel, Switzerland. This article is an open access article distributed under the terms and conditions of the Creative Commons Attribution (CC BY) license (http://creativecommons.org/licenses/by/4.0/). 